\title{
Article
}

\section{Identification of Lineage-Uncommitted, Long-Lived, Label-Retaining Cells in Healthy Human Esophagus and Stomach, and in Metaplastic Esophagus}

Pan, Qiuwei, Nicholson, Anna M., Barr, Hugh, Harrison, Lea-Anne, Wilson, George D., Burkert, Julia, Jeffery, Rosemary, Alison, Malcolm R., Looijenga, Leendert, Lin, Wey-Ran, McDonald, Stuart A.C., Wright, Nicholas A., Harrison, Rebecca, Peppelenbosch, Maikel P. and Jankowski, Janusz

Available at http://clok.uclan.ac.uk/16079/

Pan, Qiuwei, Nicholson, Anna M., Barr, Hugh, Harrison, Lea-Anne, Wilson, George D., Burkert, Julia, Jeffery, Rosemary, Alison, Malcolm R., Looijenga, Leendert et al (2013) Identification of Lineage-Uncommitted, Long-Lived, Label-Retaining Cells in Healthy Human Esophagus and Stomach, and in Metaplastic Esophagus. Gastroenterology, 144 (4). pp. 761-770. ISSN 00165085

It is advisable to refer to the publisher's version if you intend to cite from the work. http://dx.doi.org/10.1053/j.gastro.2012.12.022

For more information about UCLan's research in this area go to http://www.uclan.ac.uk/researchgroups/ and search for <name of research Group>.

For information about Research generally at UCLan please go to http://www.uclan.ac.uk/research/

All outputs in CLoK are protected by Intellectual Property Rights law, including Copyright law. Copyright, IPR and Moral Rights for the works on this site are retained by the individual authors and/or other copyright owners. Terms and conditions for use of this material are defined in the policies page. 
Manuscript Number: GASTRO-D-11-01797

Title: Identification of Lineage-Uncommitted, Long-Lived, Label-Retaining Cells in Healthy Human Esophagus and Stomach, and in Metaplastic Esophagus

Qiuwei Pan*1, Anna M Nicholson*2, Hugh Barr*3 ${ }^{3}$, Lea-Anne Harrison* ${ }^{4}$ George D Wilson ${ }^{5}$, Julia Burkert ${ }^{2}$, Rosemary Jeffery ${ }^{2}$, Malcolm R. Alison ${ }^{2}$, Leendert Looijenga ${ }^{6}$ Wey-Ran Lin ${ }^{2,7}$,

Stuart A C McDonald ${ }^{2}$, Nicholas A. Wright ${ }^{2}$, Rebecca Harrison ${ }^{4}$, Maikel P. Peppelenbosch ${ }^{1}$, and Janusz A Jankowski ${ }^{2,4,8^{\wedge}}$.* - contributed equally

Department of Gastroenterology and Hepatology, Erasmus MC-University Medical Center, Rotterdam, The Netherlands (1), Centre for Digestive Diseases, Queen Mary University of London (2), Department of Surgery, Gloucestershire Royal Hospital (3), Digestive Diseases Centre, Leicester Royal Infirmary Leicester (4), Oakland University, Beaumont Health System (5). Josephine Nefkens Institute of Pathology, Erasmus MC-University Medical Center, Rotterdam, The Netherlands (6), Department of Gastroenterology and Hepatology, Linkou Chang Gung Memorial Hospital, Chang Gung University College of Medicine, Taiwan (7), Wolfson College, Oxford (8).

\section{Contributor statement}

LH, QP, AN, JB, RJ, WL - data acquisition, HB - infusion, data acquisition, critical appraisal, GW - agent, infusion regime, appraisal , SM - data interpretation, design, writing, MA - writing, NW - concept, data interpretation, writing, QP - design, data interpretation, writing, LL - data acquisition, MP - data acquisition, design, funding, RH - data acquisition and interpretation, critical appraisal, writing JJ - concept, design, funding, data acquisition and interpretation, infusion, project supervision, appraisal, writing. 
Funding; Cancer Research UK - CRUK grant A451 to JJ, University Hospitals of Leicester, Wellcome Trust, Medical Research Council PhD studentship

Conflicts; None declared

Addressee for Correspondence;

Prof Janusz Jankowski

Sir James Black Professor

Centre for Digestive Diseases

Blizard Institute, London, E1 2AT, UK

Figures: 6

Supplemental Figures: 4

Word Count: including references 6,758

Short title: Label retaining cells in the esophagus

Keywords: adult stem cell, gastrointestinal, cancer, tissue regeneration 


\begin{abstract}
:
Background \& Aims: The existence of slowly-cycling, adult stem cells has been challenged by the identification of actively cycling cells. We investigated the existence of uncommitted, slowly cycling cells by tracking 5-iodo-2'-deoxyuridine (IdU) label-retaining cells (LRCs) in normal esophagus, Barrett's esophagus (BE), esophageal dysplasia, adenocarcinoma, and healthy stomach tissues from patients.
\end{abstract}

Methods: Four patients ( 3 undergoing esophagectomy, 1 undergoing esophageal endoscopic mucosal resection for dysplasia and an esophagectomy for esophageal adenocarcinoma) received intravenous infusion of IdU (200 $\mathrm{mg}$ per $\mathrm{m}^{2}$ body surface area, maximum dose of $400 \mathrm{mg}$ ) over a 30-min period; the IdU had a circulation $\mathrm{t}_{1 / 2}$ of $8 \mathrm{hs}$. Tissues were collected at 7, 11, 29 and 67 days following infusion, from regions of healthy esophagus, BE, dysplasia, adenocarcinoma, and healthy stomach; they were analyzed by in situ hybridization, flow cytometry, and immunohistochemical analyses.

Results: No LRCs were found in dysplasias or adenocarcinomas, but there were significant numbers of LRCs in the base of glands from BE tissue, in the papillae of the basal layer of the esophageal squamous epithelium, and in the neck/isthmus region of healthy stomach. These cells cycled slowly, because IdU was retained for at least 67 days and co-labeling with Ki-67 was infrequent. In glands from BE tissues, most cells did not express defensin-5, Muc-2, or chromogranin A, indicating that they were not lineage committed. Some cells labeled for endocrine markers and IdU at 67 days; these cells represented a small population $(<0.1 \%)$ of epithelial cells at this timepoint. The epithelial turnover time of the healthy esophageal mucosa was approximately 11 days (twice that of the intestine).

Conclusions: LRCs of human esophagus and stomach have many features of stem cells (long lived, slow cycling, uncommitted, and multipotent), and can be found in a recognized stem cell niche. Further analyses of these cells, in healthy and metaplastic epithelia is required. 


\section{Introduction}

The study of long-lived cells in the human gastrointestinal tract has been limited by experimental constraint in organised tissues. ${ }^{1-4}$ Pulse-chase experiments utilise labelled nucleotides to identify label retaining cells (LRCs) ${ }^{1,5}$ and determine the turnover time of tissues by the administration of detectable nucleoside analogues for short periods (pulse) followed by detection of the label at a later period (chase). LRCs have been previously assumed as a population that may represent the stem cells of a tissue ${ }^{2}$. This assumption follows the theory that stem cells should seek ways of protecting their genome from mutations. One way is to divide less frequently than the transit amplifying population, therefore limiting the opportunity for DNA replication errors to occur. Adult stem cells are a long-lived, multipotent population of cells responsible for the replacement of differentiated cells lost in systems with rapid cell turnover/loss and provide for regeneration after injury or insult. ${ }^{6-10}$

The area of stem cell biology is in major flux with competing and contradictory theories being reported monthly. In addition these workers use in vitro, animal and occasionally human model systems. These confusing data are particularly troublesome in the case of the esophagus and the common premalignant lesion Barrett's Esophagus (BE). First there have been reports of fast cycling cells with stem cell capacity in animal models and some of them indicate a residual stem cell population is needed while others do not ${ }^{11-15}$. Second some additional reports have implicated endodermal (including epithelial) embryonic markers in man but their relevance to human stem cells remains unclear ${ }^{16}$. Third other 'markers' have also been implicated in the epithelial mesenchymal transition of BE cells as they progress to cancer ${ }^{17}$. It remains unclear therefore whether these markers actually label stem cells or relate more to cancer stem cells. Fourth, markers like the homeobox gene $c d x 2$ appear to promote intestinalisation rather than label specific stem cells populations per $\mathrm{se}^{18}$. Fifth even the relatively simple question of the location of stem cells in the normal stomach and esophagus in man have not been previously proposed, although data is available in animal models. Despite these problems other techniques which trace lineage by genetic analyses strongly favour the likelihood of common stem cells between squamous and columnar esophageal mucosa ${ }^{19-24}$. The site of stem cells in BE has been more problematic ${ }^{10-15}$ as well as the availability of true 'biomarkers' of stem cells ${ }^{16-18}$. Furthermore it has been shown that cancer stem cells may divide quickly following recovery 
from chemotherapy thereby allowing re-expansion of resistant clones ${ }^{11}$. Therefore assessing whether stem cell turnover is different between benign, premalignant and neoplastic lesions in the same patient would be informative.

Identification of stem cells would help in the understanding of the patho-physiology of the gastro-esophageal junction. Specifically, the frequency and location of stem cells may enable their isolation for study. This could improve the diagnosis, prognostication and even the targeting of new therapies for BE.

Our aims were therefore to demonstrate that on either side of the esophago-gastric junction there are long lived undifferentiated cells ( $>11$ days) (true label retaining cells LRCs) that can periodically cycle and can also still commit to mature cell types. The availability of dysplastic and neoplastic lesions in these tissues also allowed us to study the presence of label retaining cells in various stages of disease including cancer. Therefore we aimed to assess whether LRCs could also be found in the metaplastic, dysplastic and neoplastic esophagus as well as normal mucosa. 


\section{Materials and Methods}

\section{Clinical protocol}

The Stem cell Assessment In Neoplastic Tissues (SAINT) trial was approved by the Leicestershire Ethics Board Reference Number: 09122, Medicines Health Regulatory Authority Number: CTA 21275 and Research Ethics Committee Number: 7213 in 2002 (this followed an earlier approval at the University of Birmingham Hospitals 1998). The Trial sponsor was the University Hospitals of Leicester Trust and Chief Investigator J Jankowski. Two sites were used for tissue acquisition namely Gloucestershire Royal Hospital and Leicester Royal Infirmary both in England. Four patients were recruited to the study. After informed consent was obtained an intravenous infusion of 5-iodo-2'-deoxyuridine (IdU) (gift of George Wilson, USA) at a dose of $200 \mathrm{mg}$ per $\mathrm{m}^{2}$ body surface area (maximum dose of $400 \mathrm{mg}$ ) was given over a 30 minute period and had a circulation T1/2 of 8 hours. Labelled cells therefore represent only a small proportion of the total number of cells dividing in even 24 hours. Each $200 \mathrm{mg}$ vial was reconstituted with $10 \mathrm{ml}$ of water and the resultant solution was then added to $250 \mathrm{ml}$ of $0.9 \%$ sodium chloride to generate the infusion solution. Following the infusion the vital signs were recorded and patients were monitored every 30 minutes for a further 3 hours.

\section{Patients' summary}

Patients 1 and 2 underwent esophagectomy 7 days post-infusion. Patient 3 was infused 11 days prior to surgery, Patient 4 was infused 29 days prior to an esophageal endoscopic mucosal resection (EMR) for dysplasia and an esophagectomy for esophageal adenocarcinoma, 67 days post-infusion (Supplemental Figure 1). None of the patients underwent pre-operative chemoradiotherapy. Tissues were obtained from normal esophagus, any areas of BE, dysplasia or adenocarcinoma and from normal stomach within the resection margins.

\section{In situ hybridization}

Specific localization of human leucine-rich repeat containing G protein 5 (LGR5) mRNA was accomplished by in situ hybridization using an antisense riboprobe synthesized with SP6 RNA polymerase using ${ }^{35} \mathrm{~S}-\mathrm{UTP}$ and appropriate tissue and experimental controls as previously described. ${ }^{25}$ 


\section{Tissue fixation, immunohistochemistry, immuofluorescence and flow cytometry}

Tissue was fixed and processed into paraffin blocks as per standard procedures ${ }^{24}$. We cut between 500 - 1000 sections (including intervening spares) from each block and we had approximately 10-15 blocks per patient resection and 5 for endoscopic resection (ER). Since we had 4 patients for esophagectomy and one with ER, making over 50,000 sections. Antibodies used were; IdU (IdU/BRdU) $(18.8 \mathrm{\mu g} / \mathrm{ml}$, Dako, UK), Sheep anti-IdU/BRdU (10ug/ml, Abcam,

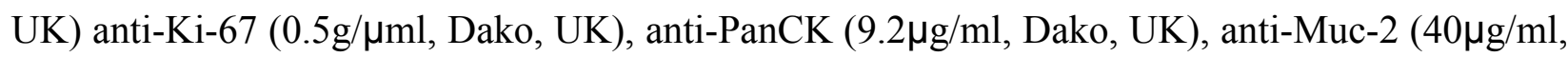
Abcam, UK), anti-Chromogranin A $(0.42 \mu \mathrm{g} / \mathrm{ml}$, Dako, UK), ATPase $(0.25 \mu \mathrm{g} / \mathrm{ml}$, Dako, UK), anti-Carbonic anhydrase II $(1 \mu \mathrm{g} / \mathrm{ml}$, Abcam, Cambridge, UK) and anti-Defensin $5(5 \mu \mathrm{g} / \mathrm{ml}$, Abcam, UK). Other antibodies to stem cell markers were employed rabbit anti-Musashi-1 $(1 \mu \mathrm{g} / \mathrm{ml}$, Millipore), LGR5 $(0.25 \mu \mathrm{g} / \mathrm{ml}$, Abgent, USA), CD133 $(1 \mu \mathrm{g} / \mathrm{ml}$, Biorbyt, UK), DCAMKL1 $(0.5 \mu \mathrm{g} / \mathrm{ml})$ (Epitomics, USA) and CDX2 (prediluted, Abcam, USA). Immunohistochemistry, immuofluorescence and flow cytometry were performed as previously described using appropriate experimental/antibodies and tissue positive and negative controls including normal stomach, intestine, skin, colon and pancreas, esophageal, gastric and colonic cancer as well as various epithelial cell lines from the squamous (OE21), columnar esophagus (OE33) as well as colorectal cancer cell lines (HCA-7, CACO-2) ${ }^{9,19-24}$.

For double-immunohistochemistry staining, mouse anti-IdU antibody (1:10 dilution) was first incubated overnight and then rabbit anti-Musashi-1 (1:75), LGR5 (1:25), CD133 (1:75) or DCAMKL1 (1:75) was incubated for 2 hours. Biotinylated anti-rabbit secondary antibody (1:250) was used to react with rabbit first antibodies. Subsequently, the section was incubated with alkaline phosphatase conjugated Avidine/Biotin complex (1:100) for 30 minutes. Fast blue staining was detected by incubation with alkaline phosphatase substrate. To detect mouse IdU antibody, biotinylated anti-mouse secondary antibody (1:150) was used. Then, the section was incubated with horse radish peroxidase conjugated Avidine/Biotin complex (1:50) for 30 minutes. Brown staining was detected by incubation with horse radish peroxidase substrate. ${ }^{4,24}$ 


\section{Results}

In this study four patients undergoing esophageal resection for adenocarcinoma were infused with 5-iodo-2'-deoxyuridine (IdU) at a dose of $200 \mathrm{mg} / \mathrm{m}^{2}$ prior to tissue collection at 7, 11, 29 and 67 days (Supplementary Figure 1). Tissues were obtained from the squamous esophagus, Barrett's esophagus, Barrett's associated dysplasia, esophageal adenocarcinoma and the normal stomach. LRCs were defined as IdU-positive cells observed at least 29 days after injection and were characterised using hematoxylin and eosin (H\&E) staining, immunohistochemistry, immuofluorescence and fluorescence activated cell sorting (FACS).

\section{IdU labelled cells in the normal squamous esophagus}

Previous work in the normal squamous esophagus has suggested that stem cells reside in the basal layer and that their progeny become differentiated in the parabasal and superficial layers eventually to become effete ${ }^{8-10}$ (Figure $1 A$ ). Cycling cells are Ki-67+ve (Figure $1 B$ ) and expression reflects cells in late G1, S, G2 and M phases: consequently a proportion of this population would have incorporated IdU at infusion. After 7 days, IdU-positive cells were identified in the basal layer $(2.3 \%)$ and in the parabasal $(6 \%)$ and superficial layers $(2 \%)$ (Figure $1 C)$, suggesting that the mucosal epithelial turnover time in the human esophagus can be greater than 7 days as many cells are still 'in upward transit'. The majority (80\%) of these labelled cells were lost by 11 days (Figure 1D). LRCs were seen mainly in the basal layer 29 days after infusion $(0.35 \%)$ (Figure $1 D)$ and this became the exclusive location by 67 days $(0.05 \%)$ (Figure $2 A$ ). These LRCs were epithelial (expressed cytokeratin) (Figure 2B) and resided adjacent to clusters of proliferating cells (Figure $2 C)$. Significantly $(p=0.001)$, IdU-positive cells in the basal layer of the squamous oesophagus were identified more frequently in the convoluted papillary basal layer (PBL) compared with the flat interpapillary basal layer (IBL) of patients 1-3 (ratio of percentage of IdU positive IBL and PBL cells; 0.4\%/1.3\% (Figure 2D); LRCs (IdU labelled) were seen especially at the tips of the papillae (Figure $2 E$ ). The papillary height increases in response to inflammation ${ }^{10}$ and here we show it contains nearly five-fold more cycling cells ( $\mathrm{Ki}-67$ labelled) than the IBL in patients $1-3(\mathrm{p}=0.0002)$. Therefore the difference 
in cycling cells between the locations may be inter-related to the difference in IdU-positive cells from which the former arise.

\section{IdU labelled cells in the normal stomach}

In the body of the stomach, it is known that cells proliferate in the neck region and migrate bidirectionally, up into the foveolus/pit and down into multiple gland bases (Figure $3 A$ ). We show that $\mathrm{Ki}-67$ expression is concentrated in the neck region of the glands (Figure $3 B$ ) and IdUpositive cells were identified at 7 days in the neck region, but also in the foveolus and base of the gland. The flux of cells appears most rapid towards the foveolus as more IdU-positive cells are in

this top region at 7 days and less towards the base (Figure 3C). LRCs were exclusively identified in the neck of the gastric unit (Figure 3D) at 11 days and these cells were epithelial (contained cytokeratin) and were also undifferentiated (Figure 3E). Interestingly, 2 IdU labelled cells, with an early parietal morphology ('fried egg' appearance but negative ATPase staining (data not shown)) were also seen in the stomach at 67 days post-infusion of IdU. The fact that they are adjacent to each other suggests that the location of the precursor cell is close to where these cells were found in the neck (Figure $3 F$ ) (IdU labelled committed cells $=$ non-LRCs). However the vast majority of stomach IdU labelled cells were lineage negative ( 99\%) (IdU labelled but non-committed cells $=$ LRCs).

\section{IdU labelled cells in the metaplastic esophagus}

Barrett's oesophagus is a premalignant condition where the stratified squamous epithelium is replaced by a columnar metaplasia: this metaplastic change may be driven by stem cells in an altered (inflamed) niche as a result of acid reflux, and so causing a lineage switch. In this regard we know that Barrett's forms glandular structures (Figure $4 A$ ); cells proliferate in the base and further up in the glands (Figure $4 B$ ) and become differentiated towards the surface before being lost into the lumen. After 7 days, IdU-positive cells were identified from the base to the midregion (Figure 4C). By 11 days the number of IdU-positive cells was reduced but were still observed in both basal and mid region (Supplementary Figure 2A). LRCs were however exclusively identified at the base of the Barrett's glands at 29 days (Supplementary Figure $2 C$ $F)(0.2 \%)$ and 67 days $(0.07 \%)$ post-infusion using IHC-hrp (Figure $4 D$ ) and IHC-fl (Figure $4 E$ ); these cells were epithelial (contain cytokeratin) (Fig. 4F), reside near to a Ki-67-positive cell 
(Figure $5 A$ ) and appear to be non-lineage committed (non-goblet cells and non-endocrine cells) (Figure 5B). The extreme basal location of LRCs within Barrett's esophagus at 67 days were akin to the proposed location of stem cells in the colon and these LRCs were also negative for defensin 5 suggesting they are not long-lived Paneth cells (Figure 5C).19 In one case a chromogranin A-positive /IdU-positive cell was identified in the gland base at 67 days (Figure 5D). A plausible explanation is that this cell may have incorporated label at time 0 , during its last division, and subsequently differentiated into a neuroendocrine cell but retained IdU since it does not divide. However, as in the normal esophagus and stomach the vast majority of IdU labeled cells in the diseased esophagus were lineage negative ( $99 \%)$ i.e. true LRCs as opposed to labelled progeny. FACS analysis was also performed on tissue at 67 days and confirmed that LRCs were present and interestingly showed that the Barrett's epithelium contained a greater proportion of LRCs than matched numbers of cells from either adjacent normal squamous or stomach tissue (Supplemental Figure 3).

Previously murine $\lg 5$ mRNA expression has been shown to be a stem cell marker in the gut in several key studies. ${ }^{1,12-13}$ Analysis for human LGR5 mRNA showed that expression was indeed located at the base of the Barrett's glands (Figure $5 E$ (light field) (dark field) $F$ )). However no expression was seen in the normal squamous esophagus or in the submucosal glands/ducts.

\section{IdU labelled cells in the dysplastic and neoplastic esophagus}

The dysplastic and adenocarcinoma tissue showed numerous IdU-positive cells at 7 days and a marked variation of staining intensity can be seen which may reflect dilution of the label after rapid division (Supplementary Figure $4 A$ and $B$ ). At 67 days post-infusion no LRCs were identified (Supplementary Figure $4 C$ and $D$ ). These data are consistent with the notion that such tumors have few, if any, slow cycling stem cells. At the very least label has fallen below detectable levels suggesting several rapid divisions in substantiation of Chen et al ${ }^{11}$.

Our data suggest that the epithelial cellular turnover time, could be different between squamous and Barrett's esophageal mucosa. In the former, $0.28 \%$ of the total mucosal compartment (i.e. both IdU labelled and unlabelled) (Figure $6 A$ ) compared with only $0.11 \%$ in Barrett's mucosa of the total mucosal compartment (Figure 6C) divided in the same period. This could be explained either by a real slower turnover of Barrett's or an artefact due to quicker turnover in Barrett's washing out the IdU label. To delve into this further it is important to understand that the Ki-67 
index is the fraction of the population in the cell cycle at the time of tissue harvesting and the IdU index is the fraction of $S$ phase cells which retain label after 11 days. Therefore the fraction of double labelled cells is the fraction of IdU-labelled cells which are then in the cell cycle again (labelled also with Ki-67) at 11days. This would also appear to be smaller in Barrett's than in the squamous esophagus. This time the few IdU labeled cells in transit up the Barrett's mucosa are in the differentiated compartment and incapable of division and therefore don't label with Ki-67. This again is consistent with a faster turning over tissue (Figure 6D). Moreover Ki-67 labelling is higher in Barrett's in percentage when compared with squamous esophagus (reported previously in 8). Furthermore in both locations some cells still retain label at 67 days, suggesting they have either not entered the cell cycle again or at best divided only once (as label is diluted easily). Consequently the number of LRCs reduced over time in both the squamous epithelium (Figure $6 E$ ), stomach (supplementary Figure 5) and Barrett's esophagus (Figure 6F). 


\section{Discussion}

We have shown for the first time the existence of a population of slowly cycling uncommitted cells in human gastrointestinal tissues ex vivo. This study relies on demonstrating that LRCs are negative for differentiation markers to be able to conclude that they are stem or progenitor cells. Previously, it is only in the oxyntic mucosa of trefoil factor-2 (TFF2) mice that successful lineage tracing has demonstrated progenitor stem cells in animal models ${ }^{26}$. Furthermore it has also been reported that the murine small intestinal and colonic crypt base columnar cells (CBCs) expressing $\operatorname{lgr} 5$, are actively cycling and are able to regenerate the entire cell population. ${ }^{1,20-21}$ We have also shown LGR5 mRNA is expressed in LRC region of the Barrett's mucosa in man.

A recent publication has shown that esophageal squamous mucosa and Barrett's esophagus can share the same mitochondrial mutations implying a common stem cell ${ }^{24}$. In this regard recent genetic lineage-tracing studies in the mouse have provided new evidence to support the existence of both rapid and slowly cycling intestinal stem cells. ${ }^{1}$ Furthermore murine LRCs are most commonly found at position +4 crypts of the small intestine, ${ }^{27}$ where the putative stem cell marker Bmi-1 is expressed ${ }^{28,29}$ however Bmi-1 was not expressed in Barrett's glands from our patients (unpublished observations) and there are insufficient numbers of LRCs to precisely determine their cell position. It is possible that two stem cell populations co-exist in the gut in an overlapping way, one rapidly cycling and the other slowly cycling and that these may be interconvertable ${ }^{29,30}$. In this regard distinct populations of slow cycling LRCs and more rapidly cycling cells have been previously characterised in both the bulge region of the hair follicle and in the intestine ${ }^{2,31,32}$. In the former case the $\lg r 5$-negative cells cells co-exist with $\lg r 5$-positive cells in the skin at the lower bulge of the hair follicle and appear to represent an active but heterogenously cycling stem cell pool. $3,33,34$

Studies have shown that rapidly cycling lgr5-positive cells divide symmetrically following a pattern of neutral drift dynamics, ${ }^{33,36}$ but do not rule out our observations of topographically distinct slowly cycling stem cell population, perhaps with both asymmetric division and subtly different niche signals maintaining the relatively inactive state. In this regard we found $<0.1 \%$ of the mucosa were LRCs, however our estimates of LRCs may be lower than the actual, because we had a short labelling period, (30minutes labelling and 8 hour $\mathrm{T}^{1} / 2$ ), relative to the cell cycle and also the threshold of detection by immunocytochemistry/immuofluorescence is challenging 29,37 . It is also possible IdU could be metabolised or degraded over time as with other nuclear 
components. Intriguingly we found no LRCs in dysplastic or neoplastic tissue confirming recent data that cancer stem cells may rapidly divide under certain circumstances ${ }^{11}$.

The evidence presented here is suggestive of a population of lineage uncommitted cells within the normal and metaplastic human upper gastrointestinal tract, yet it also highlights some important characteristics of the life span of some differentiated cell types. We have observed two cells that exhibited either chromogranin A (neuroendocrine cell with endocrine marker) or the morphology of a parietal cell (however ATPase negative) in the 67 day post infusion patient. This shows that these cells differentiated after division from a progenitor cell and remained in situ for at least 67 days indicating a substantial life span. To differentiate between a LRC stem/progenitor cell and a long lived differentiated LRC we performed dual immunohistochemistry for IdU and lineage markers. It is important to state that we consider only IdU positive, lineage-negative cells to be potential progenitor cells. The lack of bone fide gastroesophageal stem cell markers has made it difficult to conclude absolutely that LRCs are stem cells. Antibodies to LGR5 are currently unreliable and lineage tracing from a single lgr5 stem cell has only been demonstrated in the murine pylorus ${ }^{38}$. Antibodies to musashi-1 have been shown to bind to parietal cells ${ }^{39,40}$ and no lineage tracing from a musashi-1-positve cell has been published and studies using CD133 have only shown lineage tracing in the intestine not the upper gastrointestinal tract ${ }^{41}$. While a recent paper in a murine model has suggested a 'reserve' slow cycling stem cell pool is not needed to maintain and repair tissue in the esophagus, it is unclear whether slower cycling cells exist and where they could be located in man ${ }^{12,42}$. Furthermore and to substantiate this later point a recent publication has shown that in skin the epidermis slowly cycling cells exist and can repopulate the entire damaged tissue ${ }^{13}$. These experiments support the position of esophageal squamous cell LRCs identified in a murine model and take it further into man in health and disease ${ }^{43}$. Intriguingly from a recent genome wide assessment study we have shown the most important single nucleotide polymorphism is linked with FOXF1 in determining which patients develop BE. FOXF1 is a gene which is associated with stem cell fate and in particular, and relevantly, with endodermal selection ${ }^{44,45}$. We plan subsequently to micro-dissect these LRCs to see if FOXF1 or indeed Bmi1, Tert, Hopx and Lrig1 are factors dictating fate ${ }^{46}$.

In conclusion we present unique and timely data in man identifying the site of undifferentiated long lived LRCs (67 days) in the normal human esophagus and stomach as well as metaplastic 
esophagus which can also commit to mature cell types. These human LRCs are epithelial, have been seen to adjoin to a population of proliferating cells and commonly do not express markers for goblet cells, neuroendocrine cells or Paneth cells. Importantly, there are a tiny proportion $(<1 \%)$ of cells that label retain yet are positive for differentiation markers. These cells are indicative of division of a labelled progenitor cell and giving subsequent long lived differentiated cells. We have also shown that the tissue turnover time of the rest of the esophagus (non LRCs) to be at least 11 days. The exact functional and genetic nature of these LRCs has yet to be determined, but we propose that they may represent a population of slow-cycling stem cells. Future work aims to micro-dissect these cells and identify unique characteristics compared with adjacent cells. 


\section{Acknowledgements}

We would like to thank the patients and the ethics and regulatory committees for granting approval for this unique study. We would like to thank Dr Mark Anderson, City Hospital Birmingham a Medical Research Council Fellow who helped facilitate preliminary aspects of this project. We also thank Hans Stoop (Josephine Nefkens Institute of Pathology, Erasmus MC Rotterdam, The Netherlands) for technical support. 


\section{References}

1. Barker $\mathrm{N}$, van Es JH, Kuipers $\mathrm{J}$, et al. Identification of stem cells in small intestine and colon by marker gene Lgr5. Nature 2007;449:1003-7.

2. Cotsarelis G, Sun TT, Lavker RM. Label-retaining cells reside in the bulge area of pilosebaceous unit: implications for follicular stem cells, hair cycle, and skin carcinogenesis. Cell 1990;61:1329-37.

3. Fuchs E. The tortoise and the hair: slow-cycling cells in the stem cell race. Cell 2009;137:811-9.

4. Weissman IL. Stem cells: units of development, units of regeneration, and units in evolution. Cell 2000;100:157-68.

5. Bickenbach JR. Identification and behavior of label-retaining cells in oral mucosa and skin. J Dent Res 1981;60 Spec No C:1611-20.

6. Quante M, Wang TC. Stem cells in gastroenterology and hepatology. Nat Rev Gastroenterol Hepatol 2009;6:724-37.

7. Quante M, Bhagat G, Abrams JA, Marache F, Good P, Lee MD, Lee Y, Friedman R, Asfaha S, Dubeykovskaya Z, Mahmood U, Figueiredo JL, Kitajewski J, Shawber C, Lightdale CJ, Rustgi AK, Wang TC. Bile acid and inflammation activate gastric cardia stem cells in a mouse model of Barrett-like metaplasia. Cancer Cell. 2012;21:36-51.

8. Jankowski J, Hopwood D, Dover R, et al. Development and growth of normal; metaplastic and dysplastic oesophageal mucosa: biological markers of neoplasia. Eur J Gastroenterol Hepatol 1993;5:235-46.

9. Seery JP, Watt FM. Asymmetric stem-cell divisions define the architecture of human oesophageal epithelium. Curr Biol 2000;10:1447-50.

10. Jankowski JA, Harrison RF, Perry I, et al. Barrett's metaplasia. Lancet 2000;356:2079-85.

11. Chen J, Li Y, Yu TS, McKay RM, Burns DK, Kernie SG, Parada LF. A restricted cell population propagates glioblastoma growth after chemotherapy. Nature. 2012;23;488:5226.

12. Doupé DP, Alcolea MP, Roshan A, Zhang G, Klein AM, Simons BD, Jones PH. A single progenitor population switches behavior to maintain and repair esophageal epithelium. Science. 2012;337:1091-3.

13. Mascré G, Dekoninck S, Drogat B, Youssef KK, Broheé S, Sotiropoulou PA, Simons BD, Blanpain C. Distinct contribution of stem and progenitor cells to epidermal maintenance. Nature. 2012;489:257-62.

14. Wang X, Ouyang H, Yamamoto Y, Kumar PA, Wei TS, Dagher R, Vincent M, Lu X, Bellizzi AM, Ho KY, Crum CP, Xian W, McKeon F. Residual embryonic cells as precursors of a Barrett's-like metaplasia. Cell. 2011;145:1023-35. 
15. Xian W, Ho KY, Crum CP, McKeon F. Gastroenterology. Cellular origin of Barrett's esophagus: controversy and therapeutic implications. 2012;142:1424-30.

16. Stamp LA, Braxton DR, Wu J, Akopian V, Hasegawa K, Chandrasoma PT, Hawes SM, McLean C, Petrovic LM, Wang K, Pera MF. The GCTM-5 Epitope Associated with the Mucin-Like Glycoprotein FCGBP Marks Progenitor Cells in Tissues of Endodermal Origin. Stem Cells. 2012 Jul 3. doi: 10.1002/stem.1167.

17. Tomizawa Y, Wu TT, Wang KK. Epithelial mesenchymal transition and cancer stem cells in esophageal adenocarcinoma originating from Barrett's esophagus. Oncol Lett. 2012;5:1059-63.

18. Tamagawa Y, Ishimura N, Uno G, Yuki T, Kazumori H, Ishihara S, Amano Y, Kinoshita Y. Notch signaling pathway and $\mathrm{Cdx} 2$ expression in the development of Barrett's esophagus. Lab Invest. 2012;92:896-909.

19. Shen B, Porter EM, Reynoso E, et al. Human defensin 5 expression in intestinal metaplasia of the upper gastrointestinal tract. J Clin Pathol 2005;58:687-94.

20. Barker N, Huch M, Kujala P, et al. Lgr5(+ve) stem cells drive self-renewal in the stomach and build long-lived gastric units in vitro. Cell Stem Cell 2010;6:25-36.

21. Sato T, Vries RG, Snippert HJ, et al. Single Lgr5 stem cells build crypt-villus structures in vitro without a mesenchymal niche. Nature 2009;459:262-65.

22. Qiao XT, Gumucio DL. Current molecular markers for gastric progenitor cells and gastric cancer stem cells. J Gastroenterol 2011;46:855-65.

23. Barker N, Huch M, Kujala P, et al. Lgr5(+ve) stem cells drive self-renewal in the stomach and build long-lived gastric units in vitro. Cell Stem Cell 2010;6:25-36..

24. Nicholson AM, Graham TA, Simpson A, Humphries A, Burch N, Rodriguez-Justo M, Novelli M, Harrison R, Wright NA, McDonald SA, Jankowski JA. Barrett's metaplasia glands are clonal, contain multiple stem cells and share a common squamous progenitor. Gut.2012;61:1380-9.

25. Poulsom R, Longcroft JM, Jeffery RE, et al. A robust method for isotopic riboprobe in situ hybridisation to localise mRNAs in routine pathology specimens. Eur $\mathrm{J}$ Histochem 1998;42:121-32.

26. Quante M, Marrache F, Goldenring JR, et al. TFF2 mRNA transcript expression marks a gland progenitor cell of the gastric oxyntic mucosa. Gastroenterology $2010 ; 139: 2018-27$.

27. Potten CS, Owen G, Booth D. Intestinal stem cells protect their genome by selective segregation of template DNA strands. J Cell Sci 2002;115:2381-8.

28. Sangiorgi E, Capecchi MR. Bmil is expressed in vivo in intestinal stem cells. Nat Genet 2008;40:915-20. 
29. Takeda N, Jain R, LeBoeuf MR, Wang Q, Lu MM, Epstein JA. Interconversion between intestinal stem cell populations in distinct niches. Science. 2011;334:1420-4.

30. Blanpain C, Lowry WE, Geoghegan A, et al. Self-renewal, multipotency, and the existence of two cell populations within an epithelial stem cell niche. Cell 2004;118:635-648.

31. Escobar M, Nicolas P, Sangar F, Laurent-Chabalier S, Clair P, Joubert D, Jay P, Legraverend C. Intestinal epithelial stem cells do not protect their genome by assymmetric chromosome segregation. Nature 2011;1260-1260:258-9.

32. Tumbar T, Guasch G, Greco V, et al. Defining the epithelial stem cell niche in skin. Science 2004;303:359-63.

33. Jaks V, Barker N, Kasper M, et al. Lgr5 marks cycling, yet long-lived, hair follicle stem cells. Nat Genet 2008;40:1291-99.

34. Zhang J, He XC, Tong WG, et al. Bone morphogenetic protein signaling inhibits hair follicle anagen induction by restricting epithelial stem/progenitor cell activation and expansion. Stem Cells 2006;24:2826-39.

35. Lopez-Garcia C, Klein AM, Simons BD, et al. Intestinal stem cell replacement follows a pattern of neutral drift. Science 2010;330:822-5.

36. Snippert HJ, van der Flier LG, Sato $T$, et al. Intestinal crypt homeostasis results from neutral competition between symmetrically dividing Lgr5 stem cells. Cell 2010;143:134-44.

37. Itzkovitz S, Lyubimova A, Blat IC, et al. Single-molecule transcript counting of stem-cell markers in the mouse intestine. Nat Cell Biol 2012;14:106-14.

38. Barker N, Bartfeld S, Clevers H. Tissue-resident adult stem cell populations of rapidly selfrenewing organs. Cell Stem Cell 2010;7:656-70.

39. Wang T, Ong CW, Shi J, et al. Sequential expression of putative stem cell markers in gastric carcinogenesis. Br J Cancer 2011;105:658-65.

40. Nagata H, Akiba Y, Suzuki H, et al. Expression of Musashi-1 in the rat stomach and changes during mucosal injury and restitution. FEBS Lett 2006;580:27-33.

41. Snippert HJ, van Es JH, van den Born M, et al. Prominin-1/CD133 marks stem cells and early progenitors in mouse small intestine. Gastroenterology 2009;136:2187 94.

42. Kushner JA. Development. Esophageal stem cells, where art thou? Science. 2012;337:1051-2.

43. Kalabis J, Oyama K, Okawa T, Nakagawa H, Michaylira CZ, Stairs DB, Figueiredo JL, Mahmood U, Diehl JA, Herlyn M, Rustgi AK. A subpopulation of mouse esophageal basal cells has properties of stem cells with the capacity for self-renewal and lineage specification. J Clin Invest. 2008;118:3860-9.

44. Su Z, Gay LJ, Strange A, Palles C, Lescai F, Nanji M, Sasieni P, Howarth K, Trudgill N, Tucker A, Langford C, Edkins S, van de Winkel A, Peppelenbosch MP, van der Laan LJW, Kuipers EJ, Drenth J, Peters W, Reynolds J, Kelleher D, McManus R, Grabsch H, Prenen 
H, Bisschops R, Krishnadath KK, Siersema P, van Baal J, Middleton M, Gillies R, Petty R, Burch N, Bhandari P, Paterson S, Edwards C, Penman I, Vaidya K, Ang Y, Murray I, Tawil A, Morris D, Nwokolo C, Isaacs P, Rodgers C, Ragunath K, Macdonald C, Haigh C, Monk D, Davies G, Wajed S, Johnston D, , Gibbons M, Cullen S, Church N, Deloukas P, Hunt S, Gray E, Dronov S, Simon Potter, Anderson Mark, Avazeh Tashakkori-Ghanbaria, Blackwell JM, Bramon E, Brown MA, Casas JP, Corvin A, Duncanson A, Markus HS, Mathew CG, McCarthy MI, Palmer CNA, Plomin R, Rautanen A, Sawcer SJ, Trembath RC, Viswanathan AC, Wood NW, Trynka G, Wijmenga C, Cazier JB, Nicholson A, Gellatly NL, Glancy D,, Cooper S, Prew S, Hapeshi J, Ferry D, Rathbone B, Brown Julia, Love S, Brooks C, Attwood S, Watson P, Sanders S, Harrison R, Moayyedi P, deCaestecker J, Barr H, Stupka E, Peltonen L, Spencer CCA, Tomlinson I, Donnelly P, Jankowski JA. Common variants at the MHC locus and at chromosome 16q24.1 predispose to Barrett's esophagus. Nat Genet 2012;44:1131-1136.

45. D'Amour K, Agulnick A, Eliazer S, Kelly O, Kroon E, Baetge E. Efficient differentiation of human embryonic stem cells to definitive endoderm. Nature Biotechnology 2005;23:1534 -1541 .

46. Muñoz J, Stange DE, Schepers AG, van de Wetering M, Koo BK, Itzkovitz S, Volckmann R, Kung KS, Koster J, Radulescu S, Myant K, Versteeg R, Sansom OJ, van Es JH, Barker N, van Oudenaarden A, Mohammed S, Heck AJ, Clevers H. The Lgr5 intestinal stem cell signature: robust expression of proposed quiescent ' +4 ' cell markers. EMBO J. 2012;31:3079-91. 